Canadian Journal of Higher Education Revue canadienne d'enseignement supérieur

Volume 47, No. 2, 2017, pages 1 - 21

\title{
Sexual Violence on Religious Campuses
}

James R. Vanderwoerd

Redeemer University College

Albert Cheng

Harvard University

\begin{abstract}
Religious colleges and universities make up a substantial segment of the higher education landscape in North America, but the incidence of sexual violence on these campuses remains understudied. This study estimates the incidence of sexual violence on independent Christian campuses using a sample of part-time and full-time undergraduate students $(N=668)$ from eight private Christian colleges in Ontario, Canada. Using two widely used measures of sexual violence enabled comparisons with studies of self-reported incidents at secular and public colleges and universities. The findings show that $18 \%$ of women at religious colleges reported experiencing unwanted sexual contact within the past year, compared to studies of self-reported rates on secular campuses ranging from $21.4 \%$ to $31.4 \%$. Exploratory investigation of factors related to victimization suggests that religious colleges may provide a "moral community" that could reduce the risk of sexual violence.
\end{abstract}

\section{Résumé}

Quoique les universités religieuses contribuent considérablement à l'ensemble de l'enseignement supérieur en Amérique du Nord, la fréquence des agressions sexuelles sur leurs campus demeure peu étudiée. La présente étude estime le nombre d'agressions sexuelles sur des campus chrétiens indépendants à l'aide d'un échantillon d'étudiant(e)s de premier cycle à temps partiel et à temps plein $(N=688)$ provenant de huit universités chrétiennes privées en Ontario (Canada). L'utilisation de deux échelles d'agressions sexuelles fréquemment utilisées a permis de comparer notre étude à d'autres études qui traitent de la fréquence d'agressions sexuelles déclarées par les victimes dans les universités 
laïques et publiques. Nos résultats démontrent que dans les universités religieuses, $18 \%$ des femmes ont rapporté des contacts sexuels non désirés au cours de l'année dernière, comparativement à de 21,4 à 31,4\% des femmes des universités laïques ayant rapporté des agressions sexuelles. Des facteurs liés à la victimisation suggèrent la possibilité que les universités religieuses puissent offrir une « communauté morale » qui diminue les risques d'agression sexuelle.

\section{Introduction}

Despite increasing awareness and successive waves of government grants and programs in both Canada and the United States, popular media stories (Black, 2015; Parry, 2015; Sawa \& Ward, 2015; Westwood, 2016) and empirical evidence reveal that sexual violence remains persistent on campus (Adams-Curtis \& Forbes, 2004; Cantor et al., 2015; Carr, 2005; Fedina, Holmes \& Backes, 2016; Fisher, Cullen \& Turner, 2000; Krebs, Lindquist, Warner, Fisher, \& Martin, 2007). Although there has been extensive attention to documenting the occurrences and experiences of college women and to developing and evaluating prevention programs (Fleck-Henderson, 2012), most of this work has focused on large, secular, and public campuses. Koss, Gidycz, \& Wisniewski's (1987) landmark study briefly noted that the rates of reported rape by women varied significantly by the type of higher education institution. Specifically, Koss et al. (1987) found that women at religiously affiliated colleges reported rapes at half the rate (7\%) of private colleges (14\%) and major universities (17\%). Despite this finding nearly 30 years ago, the incidence of and factors related to sexual violence on religious campuses remain relatively understudied. We employ the term "sexual violence" to capture a range of unwanted sexual experiences of varying severity and intrusiveness from either known or unknown perpetrators (Adams-Curtis \& Forbes, 2004). As we discuss further below in the methods section, we distinguish between violence occurring within intimate relationships (i.e., intimate partner violence [IPV] or, synonymously, "relationship violence") and explicitly sexual experiences that victims perceive as unwanted and are considered to be a form of violence (Levy, 2008).

Defining and categorizing the religious identity of institutions of higher education is challenging (Glanzer, Rine, \& Davignon, 2013). We define institutions of higher education as religious if they have an explicitly religious mission statement that is clearly communicated and if they hire faculty and staff based on their commitment to the institution's religious mission (Burdette, Ellison, Hill \& Glenn, 2009). The ability to define a mission statement and hire on the basis of religious commitment also suggests that the governance and funding sources of the institution are independent rather than public (Jeavons, 2004; Smith, 2013). As noted in a survey of the non-profit sector in Canada, most institutions of higher education in Canada are classified as non-profit but receive the majority of their funding from government (Brownlee, Gumulka, Barr \& Lasby, 2005; Hall, Barr, Easwaramoorthy, Sokolowski, \& Salamon, 2005). Further, while many publicly funded universities in Canada had their origins in explicitly religious identification, processes of secularization since World War II have resulted in a model of higher education in Canada in which publicly funded universities no longer privilege any particular religious perspective but rather attempt to be neutral and objective (Gidney, 2004; Trick, 2015). Thus, we define institutions as private if they receive most or all of their funding from nongovernmental sources. Although there are many religiously affiliated colleges in Canada, most 
of these receive funding from government sources and are affiliated with larger public universities and therefore are not independent or private as defined by researchers who study the nonprofit sector (Salamon, 1995; Smith, 2014; Smith \& Lipsky, 1993; Trick, 2015; Wuthnow, 2004). Therefore, we do not include these institutions in our definition of private religious colleges. Private religious colleges and universities make up a substantial segment of the higher education landscape in North America and have experienced enrollment increases over the past 15 years that have exceeded public and secular institutions (Schuman, 2010; Glanzer, Carpenter \& Lantinga, 2011; Riley, 2005; Kinser et al., 2010; Smith, 2013). According to Christian Higher Education Canada (CHEC, n.d.) there are more than 17,000 students currently attending more than 35 private independent religious institutions of higher education in Canada.

Given the lack of research on sexual violence on religious higher education campuses, this study estimates the incidence of sexual violence on a multi-institution sample of private Christian colleges and universities in Canada. It seeks to answer two descriptive research questions:

1. What is the incidence of sexual violence among students at private Christian colleges and universities in Canada?

2. How does the incidence of sexual violence among women students at private Christian colleges and universities in Canada compare to available published incidence rates of sexual violence at secular and public higher education institutions?

In addition to the above descriptive research questions, this study also seeks to address a third more exploratory question:

3. What types of risk factors contribute to the probability of experiencing sexual violence among women students at private Christian higher education institutions?

This study, therefore, contributes to knowledge of sexual violence in higher education by providing improved estimates for the incidence of sexual violence specifically among students at private, Christian colleges and universities. In addition, this study contributes to theory about the importance of religion not only as an individual characteristic but also as a contextual factor influencing the experiences of sexual violence among college and university students.

\section{Literature Review}

Feminist researchers have long argued that, contrary to explanations for women's victimization based on individual characteristics, social contexts-particularly ones rooted in patriarchal culture-have a substantial influence on sexual assault and violence (Barnett, Miller-Perrin, \& Perrin, 2005; Donovan, 2000; Heise, 1998; Lawson, 2012; Levy, 2008). However, while feminist theories provide compelling explanations for macro-level violence against women, they have been less able to explain varying rates of victimization among women in similar patriarchal contexts (Heise, 1998). Thus, some researchers have explored how individual-level variables can be used in combination with contextual variables to increase explanatory and predictive power (Adams-Curtis \& Forbes, 2004; Cass, 2007; Hines, 2007; Mustaine \& Tewksbury, 2002). For example, routine activities theory suggests that while college campuses may indeed be contexts that put women at higher risk for sexual assault, differential rates of victimization can also be attributed to differences in women's daily activities. Specifically, three components must converge in 
order for a woman to be sexually assaulted: "a motivated offender, a suitable target, and an absence of capable guardians” (Cass, 2007, p. 351). Following this thinking, researchers have identified groups of activities that put women at greater risk of being sexually victimized, including proximity (e.g., higher frequency of contact with males and higher frequency of attendance at events where males are present) and recreational and leisure activities (e.g., frequency of attending parties, frequency of going to bars or pubs, frequency of attending athletic events) (Adams-Curtis \& Forbes, 2004; Cass, 2007; Mustaine \& Tewksbury, 2002).

DeKeseredy and Schwartz (2013), partly in response to criticism that routine activities theory unfairly blames women victims, shift the responsibility to men. They focus on male perpetrators by combining feminist theory with individual and contextual variables to construct their male peer support theory. They identify particular contexts and activities that increase the risk of men victimizing women, which are similar to the high-risk contexts identified in routine activities theory. Specifically, male peer support theory suggests that, within the larger context of a patriarchal culture, male participation in activities that are typical of college campuses, such as partying, heavy drinking, male-only clubs and social activities, and so on, reinforce patriarchal values and condone-even reward-men's violent and abusive behaviour toward women (Schwartz, DeKeseredy, Tait \& Alvi, 2001). Overall, then, this literature suggests that explanations of sexual violence require greater understanding of how social contexts operate to reinforce, constrain, or encourage activities and behaviours that place women at risk for sexual victimization. Although this literature makes it clear that college and university campuses are risky contexts, it does not adequately address different types of campuses and whether and how variations in campus culture might act to shape either women's routine activities or men's male peer support networks in ways that decrease the risk of women's sexual victimization.

One promising line of inquiry related to different campus contexts has been the exploration of religion as both an individual and a contextual characteristic. Early studies investigating the relationship of religiosity and family violence hypothesized that increased religiosity-specifically, conservative religiosity-was positively associated with family violence. As Brinkerhoff, Grandin, and Lupri (1992) explained, "much of the rationale for suggesting a relationship between religion and wife abuse stems from the assumption that members of more fundamentalistic groups tend to be more patriarchal" (p. 17).

Researchers have found support for a relationship between religiosity and attitudes about violence, such as acceptance of rape myths (Giovannelli \& Jackson 2009; Jankoski, Johnson, Damron \& Smischney, 2011), approval of violence (Koch \& Ramirez, 2010), empathy for sexual violence victims (Berkel, Vandiver \& Bahner, 2004), and acceptance of patriarchal gender relationships (Neal \& Mangis, 1995). Despite these empirical associations between religious beliefs and attitudes related to violence, other researchers have demonstrated that increased religiosity is actually related to lower rates of reported victimization or perpetration of sexual violence (Ellison, Trinitapoli, Anderson, \& Johnson, 2007; Ellison \& Anderson, 2001; Ellison, Bartkowski, \& Anderson, 1999; Wang, Horne, Levitt, \& Klesges, 2009). Taken together, these findings suggest that the relationship between religion and sexual violence is a complex one. While there is empirical support for links between holding religious beliefs, being conservative, and retaining traditional views on the one hand, and attitudes and beliefs that appear to support or condone inti- 
mate partner violence on the other hand, these links do not appear to result in increased experiences of sexual violence (with one exception: Koch and Ramirez (2010) found that Christian fundamentalism is associated with higher incidence of IPV).

One possible limitation of these findings is that they all conceptualize religion primarily as an individual variable. There is some preliminary evidence that when religion is conceptualized or measured as part of the context (e.g., a campus or a county that is predominantly religious) rather than as an individual characteristic, it may be a factor in differing incidence rates of IPV (Ginn, Walker, Poulson, Singletary, Cyrus \& Picarelli, 1998; Koss et al., 1987). However, it is unclear whether it is the religious character of the college or its location (rural versus urban) that is more salient in explaining sexual violence (Vanderwoerd, 2009). In related investigations of religious campuses, qualitative researchers have found that religious colleges provide a powerful cultural context that influences students' attitudes and beliefs about gender roles and IPV, even when such attitudes and beliefs conflict with views in the broader society (Bryant, 2006, 2009; Lidzy, 2005).

\section{Religion as a Contextual Variable: Moral Communities}

Another line of inquiry has been pursued by researchers investigating the influence of religion as a contextual variable in related areas including deviance, delinquency, sexual behaviour and religious participation. Stark (1996) challenged the notion that religion had little effect on delinquent behaviour by exploring religion not as an individual characteristic, but rather as a collective context that defined the reality, and therefore shaped the behavior, of those in a given religious community. Describing these religious contexts as "moral communities" (1996, p. 166), Stark found that belonging to religious communities did, in fact, have an influence on reducing delinquent behaviour. Subsequent research has continued to find empirical support for Stark's moral community theory. Regnerus (2003) found that adolescents with higher individual religious commitments were less likely to engage in specifically delinquent behaviour when they were in homogenous religious contexts (high schools, and counties) that reinforced behaviours consistent with individual religious beliefs. Regnerus (2003) and Hill (2009) also showed that Protestant religious college contexts were more likely to have an influence on students' behaviour compared to Catholic colleges.

More pertinent to this study's focus on sexual behaviour, several studies have observed that religious campuses, specifically ones identified as Protestant and evangelical, have a clear impact on students' sexual activities and choices. For example, Freitas (2008, 2013) interviewed students at four types of higher education institutions-public, private-secular, Catholic, and evangelical-and reported that, "The only institutions at which I encountered a shared identity and common values-which I now believe are keys to a healthy college experience, especially when it comes to reining in hookup culture-were the two evangelical colleges" (2008, p. 67). Echoing Freitas' observations, Riley (2005) and Daloz Parks (2000) also explored the impact that religion can have on students' behaviours and lifestyle, particularly when it is part of a collectively shared social context. Although Freitas (2008), Riley (2005), and Daloz Parks (2000) all draw their arguments from anecdotal or less systematic evidence, their observations are supported by more rigorous empirical evidence. Analyzing a national sample of U.S. college women, Burdette et al. (2009) explored the influence of religion, both as an individual and a contextual variable, on women's 
"hooking up" behaviour. They found that students at Protestant religious colleges were less likely to hookup compared to students at Catholic institutions or institutions with no religious affiliation. The authors suggest that with respect to casual sexual activity, "Protestant colleges and universities may be more effective in establishing "moral communities" (Burdette et al., 2009, p. 546). They further argue that a common set of lifestyle practices and policies at these Protestant colleges operate to create and sustain moral communities that "contribute to a climate of sexual restraint" (p. 538). These practices and policies, which are common at Protestant and evangelical colleges, include voluntary or mandatory attendance at religious services; additional courses in religion; guidelines and parameters for behaviours, such as the consumption of alcohol, sexual relationships, and between-sex interactions; single-sex on-campus residences (Freitas, 2008, 2013; Riley, 2005).

Besides formal institutional policies, there are other possible influences on student behaviour. Informal social norms derived from regular interactions among members within religious campuses may also play a role. Scholars have long argued that these communal factors explain differences between U.S. Catholic schools, secular private schools, and traditional public schools in student and teacher behaviour (Bryk, Lee, \& Holland, 1993; Coleman, Hoffer \& Kilgore, 1982). Specifically, members of a community adopt or refrain from certain behaviours by observing other members in the community who serve as role models. Role models for college students can be, for example, faculty or other students. By paying close attention to what behaviours are rewarded or sanctioned in particular contexts, students learn social norms and identify behaviours that are appropriate or inappropriate (Bandura, 1977; Paluck \& Shepherd, 2012; Sheriff \& Sheriff 1964). A religious college where moral principles and values are more salient than a secular community may enhance the clarity, formation, and maintenance of a distinctive community. This communal characteristic ultimately influences the behaviour of its members. Religious colleges may be examples of this kind of community where communal factors influence student behaviour.

Our review of the relevant literature and theory therefore suggests that religious higher education institutions may provide a "moral community" that could reduce the risk of being victimized by sexual violence. Specifically, Protestant evangelical colleges have policies and practices, including informal cultures, that draw on these colleges' religious beliefs ,which set them apart from their secular counterparts. Given the lack of systematic research on the incidence of sexual violence among students at religious colleges, this study contributes to the literature by providing improved estimates of the incidence of sexual violence on private, religious college campuses, as well as exploring the factors related to sexual violence victimization that contributes to knowledge and theory about religion and moral communities in higher education.

\section{Method}

\section{Population and Sample}

Participants were recruited from eight private, independent Christian colleges in Ontario: two are members of or affiliated with the Council of Christian Colleges and Universities (CCCU, n.d.), and six are members of or affiliated with Christian Higher Education Canada (CHEC, n.d.). Both the CCCU and CHEC are associations of Christian institutions of higher education that have criteria for membership consistent with Protestant evangeli- 
cal Christianity. Each of the participating colleges has policies and practices for student lifestyle and conduct that are based on religious values and are consistent with the practices identified in the literature about moral communities. After receiving ethics approval from the primary author's university regarding human subjects research, all undergraduate students enrolled either part time or full time during the 2008-2009 academic year were invited to participate via email. An online, anonymous self-report survey design was used to reduce barriers respondents might feel in disclosing sensitive or stigmatizing experiences (Brock, Barry, Lawrence, Rolfs, Cerretani, \& Zarling, 2015; Krebs, Lindquist, Warner, Fisher, Martin, \& Childers, 2011). To preserve anonymity, researchers partnered with campus student affairs personnel to email an invitation to participate with a link to an online survey. After the initial invitation during the fall semester, three additional reminders were sent out by email approximately every month, with data collection concluding midway through the winter semester. The combined estimated undergraduate enrollment of all participating institutions was 1,800 (ranging in size from 15 to 800). The overall response rate was $43.1 \%$ (ranging from $31.2 \%$ to $51.2 \%$ ), which allows for generally acceptable estimates for survey research (Fowler, 1993), yielding a usable sample of 668.

\section{Measures}

To permit comparisons with previous studies, two measures of sexual violence with well-established validity and reliability were selected, both of which have been used extensively with campus populations. Unwanted sexual experiences were measured with the Sexual Experiences Survey (SES), developed by Koss and colleagues (Koss \& Gidycz, 1985; Koss \& Oros, 1982) in the 1980 os to provide better estimates of rape and related unwanted sexual experiences that more closely corresponded to legal definitions of sexual assault. The SES has been widely used by researchers investigating the incidence and prevalence of sexual victimization, particularly with college students (Cook, Gidycz, Koss, \& Murphy, 2011; Koss et al., 1987; Koss et al., 2007; Testa, VanZile-Tamsen, Livingston, \& Koss, 2004). The SES uses items describing specific behaviours in which participants identify whether they have experienced particular actions.

Relationship violence was measured with the Conflict Tactics Scale (CTS) (Straus, 1979, 1990), which is widely used for measuring relationship conflict and violence with a wide variety of populations (Straus, 2012), including college and university students (Straus, 2004a, 2004b). To limit response fatigue, the revised short form was used. Straus and Douglas (2004) report that the revised short form scale can be scored on five subscales: negotiation, physical assault, injury, sexual coercion, and psychological aggression. The CTS posits that conflict in relationships exists on a continuum from psychological aggression (insults, manipulation, etc.) to physical attacks and sexual assault. As is made clear in the lead-in to the CTS, Straus $(1979,1990)$ posits that all couples use a variety of approaches to manage conflict. Thus, the CTS is a useful measure because of its widespread use as well as its nuanced conceptualization of relationship violence.

\section{Analytical Strategy}

To answer the first research question (what is the incidence of student sexual violence at Canadian Christian colleges/universities?) we calculated the percent of respondents reporting various types of sexual violence. Following previous researchers (Koss et al., 
1987; DeKeseredy \& Kelly, 1993; Schwartz \& DeKeseredy, 1997), we defined incidence as the number of episodes within the past year (as opposed to prevalence, which they define as episodes in one's lifetime since age 14).

To answer the second question (how do the rates of sexual violence of women students at Canadian Christian colleges compare with reported rates of women in secular higher education institutions?), we compared rates of the incidence of relationship violence and unwanted sexual experiences for women in our sample with incidence rates published in the literature. It is well documented that rates of sexual violence vary widely, depending on whether incidences are self-reported, gathered through various secondary means such as institutions' crime reports, or disclosed to third persons (Cantor et al., 2015; Cook et al., 2011; Fedina et al., 2016; Krebs et al., 2011; McCallum \& Peterson, 2016). Therefore, we restricted our comparison to only those studies that used the SES in a self-report survey design in a manner similar to our study.

Finally, to answer the third research question (what risk factors contribute to the reported rates of sexual violence?), we investigated what types of risk factors were associated with the incidence of sexual violence. In our survey, we asked women to indicate how often they engaged in certain behaviours that, according to prior research (as noted above in our review of the literature), increased the risk of becoming a victim of unwanted sexual experiences. Women indicated the frequency to which they

1. Go to a party where alcohol is served,

2. Go to a club, bar, or pub,

3. Become drunk,

4. Are inside an all-male residence hall or floor,

5. Are inside campus residences when only males are present, and

6. Go to parties attended by male student athletes.

The first three risky behaviours captured alcohol use, while the latter three risky behaviours captured association with males or male athletes. Respondents answered these survey items on a six-point scale with the following answer choices:

1. Never

2. Less than once a month

3. Once a month

4. Once or twice each week

5. More than twice a week, or

6. Daily or almost daily.

We compared women who reported habitually engaging in each type of risky behaviour (at least once or twice each week) to those who reported not habitually engaging in the same risky behaviour (once a month or less). We preferred and reported our particular threshold (e.g., at most once a month versus at least once or twice each week) because in our judgment, this threshold possessed the most face validity when dichotomizing two types of people. Nonetheless, patterns were similar if we chose different thresholds to construct our comparison groups. We used logistic regressions, controlling for several background characteristics (race, socioeconomic status, year in school, living arrangements, and college attended) to compute predicted probabilities of experiencing any form of unwanted sexual experiences, conditional on whether an individual habitually engages in a particular risky behaviour or not. That is, holding all control variables constant at 
their respective means, we computed interval estimates for the likelihood that women who engaged in each type of risky behaviour at least once or twice a week experience unwanted sexual experiences. We did the same for women who engaged in each type of risky behaviour once a month or less. By estimating models that adjust for background demographic characteristics, our analysis compared two hypothetical individuals who do not differ in those observable ways except for the fact that one engaged in particular risky behaviours at most once a month, while the other engaged in the same risky behaviour at least once or twice each week.

\section{Results}

Reflecting broader trends in higher education in which women outnumber men, nearly $60 \%$ of students in the sample were women. Further, as shown in Table 1, the mean age of respondents was 22.4 years ( $S D=5.8$ ) with $80.3 \%$ single (unmarried), and 50.4\% reported no intimate or dating relationship. Eighty-four percent were full time students, and nearly half (46.5\%) lived on campus. There was relatively little ethnic diversity in the sample, with $83.6 \%$ describing their ethnic identity as European background or heritage.

More than $20 \%$ of respondents reported experiencing some form of sexual violence victimization in the past year. Table 2 displays the reported experiences of sexual violence according to four categories of responses from the SES:, unwanted sexual contact from partner, coerced sexual intercourse, attempted rape, and rape. There were also few differences between men and women in reported sexual violence.

As shown in Table 3, responses on the CTS indicate that among students who were in a current intimate committed relationship $(N=378), 55.6 \%$ reported experiencing some form of relationship violence (including both verbal and physical violence). Just over half (51.2\%) reported experiencing psychological aggression from their partner (defined by the CTS as insults, yelling, threatening, or destroying belongings), while nearly one quarter (24\%) reported suffering physical assault by or a physical injury from their partner.

Comparing reported sexual violence on Christian campuses in this study with studies using comparable measures revealed that sexual violence occurred less frequently in our sample of students from Christian colleges compared to reported incidence on secular campuses. For example, three studies with large national samples in Canada or the USA used the SES in self-report survey designs to estimate the incidence of sexual violence. They reported that 22.8\% (DeKeseredy \& Kelly, 1993, p. 149), 21.4\% (Schwartz \& DeKeseredy, 1997, p. 16) and 27.8\% (Koss et al., 1987, p. 168) of women experienced unwanted sexual contact within the past year. Fedina et al. (2016) systematically reviewed campus sexual violence studies published from 2000 to 2015, limiting their search only to studies that used self-reported accounts of sexual violence. Of the 34 studies included in their review, six used the SES to measure sexual violence within the past year. The average incidence of unwanted sexual violence reported by women in these six studies was $31.4 \%$. All of these studies' estimates, using the SES in self-report surveys as we did, reported the incidence of unwanted sexual contact at higher rates (ranging from $21.4 \%-31.4 \%$ ) than the $18 \%$ reported by women in our study (see Table 2). Further, while $0.5 \%$ of women in our study reported being raped within the past year (see Table 2), the studies above (DeKeseredy \& Kelly, 1993, p. 149; Fedina et al., 2016; Koss et al., 1987; Schwartz \& DeKeseredy, 1997, p. 16) found that women's reports of being raped within the past year ranged from $3.4 \%$ to $4.9 \%$. 
Table 1. Selected Demographic Characteristics of Sample from Eight Ontario Christian Colleges $(N=668)$

\begin{tabular}{|c|c|c|}
\hline Demographic characteristic & $\begin{array}{l}\text { Range among colleges } \\
\text { (minimum - maximum) }\end{array}$ & Percent* \\
\hline Gender (\% female) & $33 \cdot 3-68.6$ & 59.7 \\
\hline Mean Age in Years (S.D.) & $20.6(3.3)-30.7(7.3)$ & $22.4(5.8)$ \\
\hline \multicolumn{3}{|l|}{ Ethnicity } \\
\hline European & $60-90.8$ & 83.6 \\
\hline Asian & $0-40$ & 4.6 \\
\hline Central, South American, Caribbean & $0-4.7$ & 1.8 \\
\hline African \& Arabic & $0-4 \cdot 3$ & 1.8 \\
\hline Aboriginal & $0-7.7$ & 1.9 \\
\hline Unknown or no response & $0-11.4$ & 6.3 \\
\hline Attending fulltime ( 4 or more courses) & $33 \cdot 3-94.7$ & $84 \cdot 3$ \\
\hline Living on campus & $5.2-64.4$ & 46.5 \\
\hline \multicolumn{3}{|l|}{ Living arrangements } \\
\hline live alone & $0-26.0$ & 7.6 \\
\hline friends / roommates & $0-76.6$ & 56.4 \\
\hline family / relatives / spouse & $19.1-90.0$ & 32 \\
\hline other & $0-33$ & $3 \cdot 9$ \\
\hline \multicolumn{3}{|l|}{ Year of study } \\
\hline $1^{\text {st }}$ year & $16.7-53.8$ & 28.8 \\
\hline $2^{\text {nd }}$ year & $20.5-33.3$ & 24.8 \\
\hline $3^{\text {rd }}$ year & o- 33.3 & 21.4 \\
\hline $4^{\text {th }}$ year or more & $0-22$ & 17.6 \\
\hline \multicolumn{3}{|l|}{ Marital status } \\
\hline Single, never married & $55.2-86.5$ & 80.3 \\
\hline Engaged to be married & $0-6.3$ & $4 \cdot 9$ \\
\hline Married & $6.9-40$ & 13.2 \\
\hline Living together & $0-1.7$ & 0.4 \\
\hline Separated or divorced & $0-3.4$ & 1.1 \\
\hline \multicolumn{3}{|l|}{ Relationship status } \\
\hline $\begin{array}{l}\text { Committed, intimate relationship } \\
\text { for } 1 \text { year or more }\end{array}$ & $16.7-48.3$ & $34 \cdot 5$ \\
\hline $\begin{array}{l}\text { Committed, intimate relationship } \\
\text { for } 1 \text { year or less }\end{array}$ & $6.9-16.7$ & 10.5 \\
\hline Dating but no one seriously & $0-16.7$ & 4 \\
\hline No intimate or dating relationship & $41.4-54 \cdot 3$ & 50.4 \\
\hline
\end{tabular}

Note. *indicates that all figures in this column show percent unless otherwise noted 
Table 2. Percent of persons reporting experiences of sexual violence (as measured by the Sexual Experiences Survey) within the past year $(N=668)$

\begin{tabular}{lccr}
\hline & \multicolumn{2}{c}{ Gender } \\
\cline { 2 - 3 } Sexual violence experience & $\begin{array}{c}\text { Male } \\
(\mathrm{N}=269)\end{array}$ & $\begin{array}{c}\text { Female } \\
(\mathrm{N}=399)\end{array}$ & Total \\
\hline Unwanted sexual contact from partner & 19 & 18 & 18.4 \\
Coerced sexual intercourse & 1.9 & 2.8 & 2.4 \\
Attempted rape & $\mathrm{O}^{*}$ & $2^{*}$ & 1.2 \\
Rape & 0 & 0.5 & 0.3 \\
Any one or more of the above & 19.7 & 20.8 & 20.4 \\
No reported sexual violence & 80.2 & 79.2 & 79.6 \\
\hline
\end{tabular}

Note. ${ }^{*}$ indicates difference between males and females statistically significant $(\mathrm{p}<.05)$

Table 3. Percent of persons reporting relationship conflict and violence (as measured by Conflict Tactics Scale) within past year $(N=378)$

\begin{tabular}{lccc}
\hline & \multicolumn{2}{c}{ Gender } & \\
\cline { 2 - 3 } Relationship conflict and violence & $\begin{array}{c}\text { Male } \\
(\mathrm{N}=151)\end{array}$ & $\begin{array}{c}\text { Female } \\
(\mathrm{N}=227)\end{array}$ & Total \\
\hline $\begin{array}{l}\text { Used psychological aggression (insults, yell- } \\
\text { ing, destroying or threatening) }\end{array}$ & 49.7 & 52.3 & 51.2 \\
$\begin{array}{l}\text { Physically assaulted partner (pushed, } \\
\text { shoved, slapped, punched, kicked, beat up) }\end{array}$ & 14.8 & 20.4 & 18.1 \\
$\begin{array}{l}\text { Suffered an injury as a result of a conflict } \\
\quad \text { with partner }\end{array}$ & 6.6 & 5.5 & 5.9 \\
$\begin{array}{l}\text { Experienced sexual coercion with partner } \\
\begin{array}{l}\text { Experienced any one or more of psychologi- } \\
\text { cal, physical, or sexual violence or injury }\end{array}\end{array}$ & 8.6 & 12.2 & 10.7 \\
\hline
\end{tabular}

Note. Differences between male and female not statistically significant $(p>.05)$

Addressing our third research question, Figure 1 displays the predicted probabilities of experiencing unwanted sexual experiences (as measured by the SES) for females who engaged in various types of risky behaviour. The probabilities are estimates that are calculated after running a logistic regression. We compared the probabilities for women who engaged in each risky behaviour at most once a month (represented by the first bar) to the probabilities for women who engaged in the same behaviour at least once or twice each week (represented by the second bar). We also display 95\% confidence intervals for each predicted probability, which has been adjusted for observable background characteristics 
that may also contribute to the likelihood of unwanted sexual contact. As shown by the first three pairs of bars, it appears that risky behaviour associated with alcohol consumption is related to an increased likelihood of having unwanted sexual experiences. Take the first set of bars as an example. Women who at most once a month attended parties where alcohol is served had a $20 \%$ chance of having unwanted sexual experiences. The rate is nearly three times as high (60\%) for women who attended similar types of parties at least once or twice each week. As indicated by the non-overlapping $95 \%$ confidence intervals, the difference between these two groups of women is statistically significant at conventional levels. We found similar results comparing women who visited clubs or bars and women who became drunk with varying frequency. Women who engaged in these risky behaviours once a month or less all had a 20\% likelihood of having unwanted sexual experiences. However, the probability increased to almost $60 \%$ for women who visited clubs or bars at least once or twice a week and to over $70 \%$ for women who became drunk at least once or twice each week. Note, too, that despite the large confidence intervals we were able to rule out the possibility that these differences were due to statistical chance.

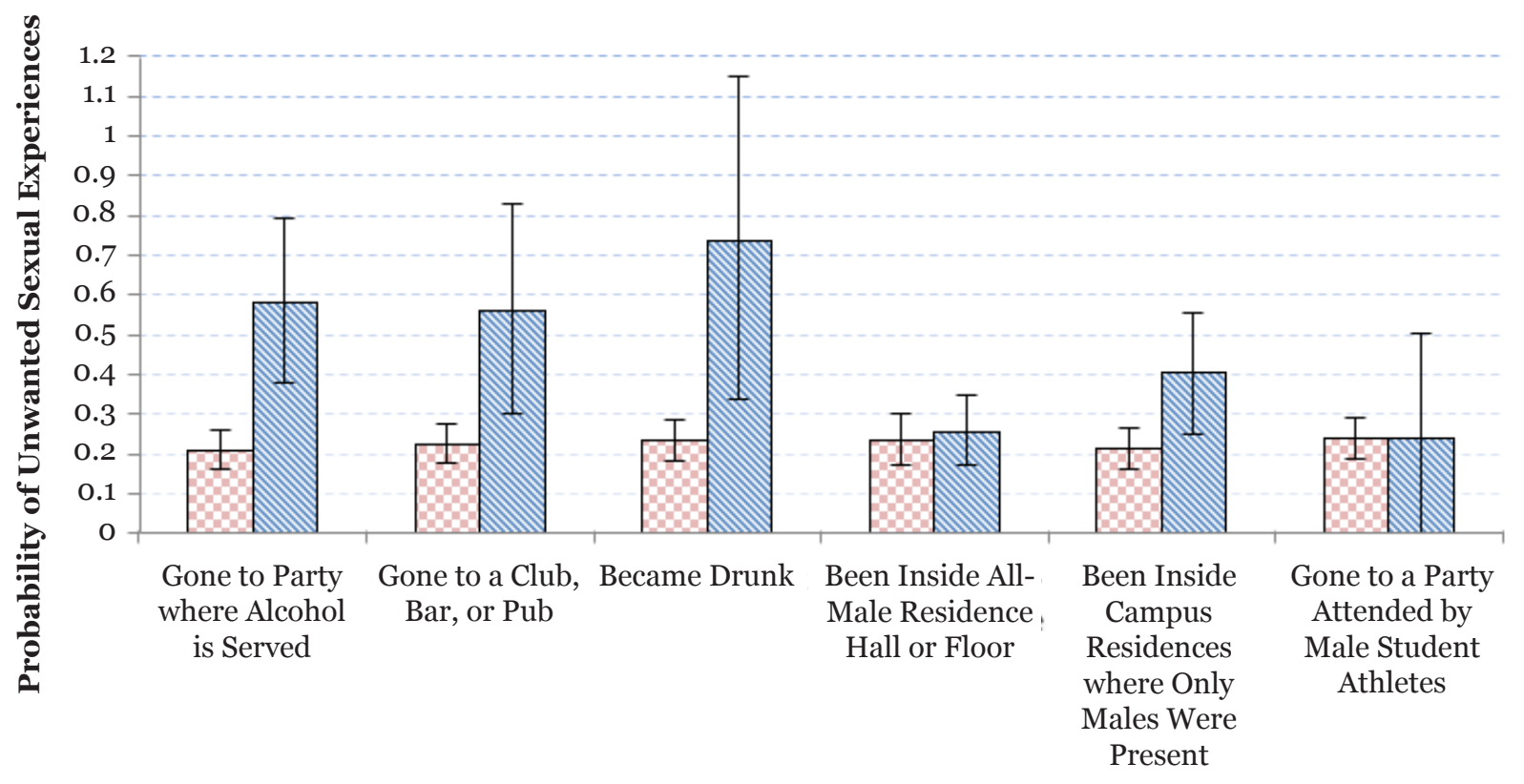

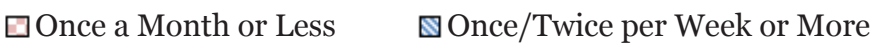

Figure 1. Probability of women's unwanted sexual experiences by risk factors $(\mathrm{N}=342)$. Probabilities are derived from marginal effects calculated after running a logistic regression for each of the six risky behaviors. Logistic regression equations control for student's gender, year in school, race, socioeconomic background, whether they live on or off campus, college attended, and whom they live with.

Engaging in risky behaviours related to male association does not appear to influence the likelihood of having unwanted sexual experiences. Regardless of the frequency with which women were inside all-male residence halls or went to parties attended by male student athletes, the likelihood of encountering unwanted sexual experiences was about 
20\%. An exception is women who more frequently were inside campus residence halls when only males were present had a $40 \%$ probability of having unwanted sexual experiences. This probability was twice as large as the probability for the comparison group. Although substantively large, the difference just missed statistical significance at the $95 \%$ confidence level.

\section{Discussion}

With almost weekly media stories of sexual violence on university and college campuses across North America, there is heightened urgency to seek greater understanding of this persistent problem in higher education. Although there is extensive research on secular and public campuses, there is much less awareness of private, religious campuses. This study addresses this gap by estimating the incidence of sexual violence on religious campuses and comparing them to similar incidence rates of self-reported sexual violence at secular campuses. This study additionally investigates unique characteristics of religious colleges and universities that might explain differing incidences of sexual violence compared to public secular institutions.

The results of this study reveal that there is no doubt that sexual violence occurs on Christian campuses. However, even though it is clear that Christian colleges are not immune to sexual violence, the incidence of sexual violence is lower among women in our study than that reported on secular campuses in studies using similar measures and selfreport survey designs. What might explain the differences between the incidence of sexual victimization on these Christian campuses compared to the incidence rates reported in secular campuses? Our exploration of factors related to sexual violence victimization lends support to theoretical approaches focusing more on contextual factors as opposed to individual characteristics. In particular, our study lends support to the "moral communities" thesis first posited by Stark and subsequently extended and confirmed by Regnerus (2003), Hill (2009), and-more directly relevant to sexual behaviour-Burdette et al. (2009). If, as Burdette and colleagues suggest, a Protestant evangelical college is a moral community that contributes to "a climate of sexual restraint," (p. 538) then one would expect to observe some evidence of such restraint, particularly with respect to risk factors that have been found to be highly related to sexual violence victimization. Two factors identified in the literature are (1) alcohol-related activities and behaviours, and (2) association with and proximity to males and male athletes (Adams-Curtis \& Forbes 2004; Barnett et al., 2005; Krebs et al., 2007). The association between alcohol and sexual violence victimization has been widely documented, particularly as part of the culture of college and university campuses (Carr, 2005; Mohler-Kuo, Dowdall, Koss \& Wechsler 2004; Nicholson et al., 1998). Male association and proximity has also been shown to be related to women's victimization. Routine activities theory suggests that a variety of circumstances must converge in order for women to be victimized, including being in the presence of men and being in a social context in which there is an absence of peers or authority figures who could act as restraints on men's violent behaviour (Cass, 2007; Mustaine \& Tewksbury, 2002). Further, some researchers have shown that male peer networks on college campuses, especially those associated with fraternities or athletics, foster attitudes and condone behaviours in which victimizing women is seen as normal or even praiseworthy (Adams-Curtis \& Forbes, 2004; DeKeseredy \& Schwartz, 2013; Schwartz et al., 2001). 
An examination of the relationships between alcohol use and male association as risk factors in women's sexual violence victimization in our study reveals tentative support for the moral community thesis. Religious colleges, particularly Protestant evangelical ones such as the institutions in our study, typically attempt to create a campus community shaped by and adhering to religious beliefs and values (Burdette et al., 2009; CCCU, n.d., Freitas, 2008; Riley, 2005). This adherence often takes the form of guidelines and regulations that attempt to limit or constrain the use of alcohol, as well as the contact and timing of relationships between men and women through such means as curfews and single-sex residences. We found that women who engaged in alcohol-related activity more than once a week had higher rates of victimization of unwanted sexual experiences compared to women who engaged in alcohol-related activity once a month or less. Thus, as in secular campuses, alcohol remains a risk factor for sexual violence victimization on religious campuses, despite restrictions on alcohol use on these campuses. However, we did not find a corresponding influence of male association on women's sexual violence victimization. Instead, it appears that on religious campuses male association is not a risk factor for victimization. Put simply, while on secular campuses being in the presence of males poses a sexual victimization threat for women, this appears to be less so for women on private religious campuses. The moral communities thesis would suggest that this is related to religious campuses creating conditions in which men and women appear to have internalized and acted upon the parameters for sexual restraint that are part of their faith's traditions and teachings. At the same time, however, the association of alcoholrelated activity with increased sexual violence suggests a breakdown in the moral community on these religious campuses.

\section{Implications}

The findings of this exploratory study suggest that although women at private religious colleges may be at lower risk of sexual violence than their counterparts in secular campuses, sexual violence is still a pressing concern on these religious campuses. This study reveals that leaders at religious colleges must not be complacent about the realities of sexual violence, nor be lulled into thinking that these problems only happen "out there." On the contrary, student development staff on Christian campuses can use these findings to raise awareness of the risks of sexual violence and prompt internal and external stakeholders to develop programs to prevent and respond to sexual violence on their campuses, based on best practices developed in secular and public colleges (Fleck-Henderson, 2012; Quinlan, Clark, \& Miller, 2016). Further, this study confirms that alcohol remains a risk factor for sexual violence victimization, even on religious campuses where attempts are made to restrict the use of alcohol. This finding should prompt student development staff to reexamine their campus alcohol policies to explore how the effectiveness of programs and interventions to limit alcohol and alcohol-related activities can be improved. One implication is that religious campuses that restrict alcohol could be more aware of the link between alcohol and sexual violence and tailor programs to make this link more explicit. On the other hand, our findings suggest that association with males and male athletes may not be a risk factor on religious campuses compared to secular campuses. We suggest that this may be related to religious campuses, which intentionally create moral communities that attempt to cultivate sexual restraint. Such restraint clearly goes against the trend in 
secular higher education where sexual exploration and casual sex are the norm (Burdette et al., 2009; Freitas 2008, 2013). Although the idea of sexual restraint is widely viewed by the dominant culture as anachronistic and even repressive (Brown, 2012; Cohen, 2012; Eberstadt, 2012), our study suggests that a moral community of restraint may be linked to increased safety from sexual violence on campuses. Given the tentative nature of our results, however, more research that tests this proposition is warranted.

The limitations of this exploratory study should prompt further research to greater understand sexual violence on religious colleges. For example, additional research should seek to replicate these findings on larger and more nationally representative samples, paying particular attention to how variations in measures and design influence reported incidence (Cantor et al., 2015; Cook et al., 2011; Fedina et al., 2016; Krebs et al., 2011; McCallum \& Peterson, 2016). Such research would need to carefully define and measure the religious nature of colleges, since such labels may mask many important factors that are relevant to sexual violence. In addition, it would be important to attempt to identify and further explore the characteristics of religious colleges that set them apart from other colleges and are implicated in incidences of sexual violence. Following the lead of previous researchers (Burdette et al., 2009; Freitas, 2008), one direction would be to study students at different types of campuses (public secular, private non-religious, Catholic, Protestant evangelical) to enable better comparisons between the incidence of sexual violence at different types of campuses. A key area for further investigation would be to explore whether the differences in sexual violence between religious and other colleges are due to individual religious differences among students (i.e., selection bias) independent of the specific characteristics of colleges themselves. Another area for further investigation should address sexual assault and violence in religious colleges among persons who are LGBTQ. As noted by several researchers, the intersection of religion and sexual orientation among college students is fraught with challenges that demand further research (Chonody, Woodford, Smith, \& Silverschanz, 2013). Whether individual, institutional, or both, however, this study makes it clear that both religious and secular colleges must continue to face up to the realities of sexual violence on campus-an issue that demands attention both by scholars and practitioners in higher education.

\section{Acknowledgements}

This research was supported by the Redeemer Centre for Christian Scholarship.

\section{References}

Adams-Curtis, L. E., \& Forbes, G. B. (2004). College women's experiences of sexual coercion: A review of cultural, perpetrator, victim, and situational variables. Trauma, Violence, \& Abuse, 5(2), 91-122.

Bandura, A. (1977). Social learning theory. Englewood Cliffs, NJ: Prentice Hall.

Barnett, O., Miller-Perrin, C. L., \& Perrin, R. D. (2005). Family violence across the lifespan: An introduction, 2nd Ed. Thousand Oaks, CA: Sage.

Berkel, L. A., Vandiver, B. J., \& Bahner, A. D. (2004). Gender role attitudes, religion, and spirituality as predictors of domestic violence attitudes in white college students. Journal of College Student Development, 45(2), 119-133. 
Black, D. (2015). A campus climate of fear. iPolitics. Retrieved from http://www. ipolitics.ca/2015/02/11/a-campus-climate-of-fear/

Brinkerhoff, M. B., Grandin, E., \& Lupri, E. (1992). Religious involvement and spousal violence: The Canadian case. Journal for the Scientific Study of Religion, 31(1), 15-31.

Brock, R. L., Barry, R.A., Lawrence, E., Rolffs, J., Cerretani, J., \& Zarling, A. (2015). Online administration of questionnaires assessing psychological, physical, and sexual aggression: Establishing psychometric equivalence. Psychology of Violence, 5(3), 294-304.

Brown, C.(2012).Religionandthedemographicrevolution: Womenandsecularisation in Canada, Ireland, UK, and USA since the 196os. Woodbridge, UK: Boydell Press.

Brownlee, B., Gumulka, G., Barr C., \& Lasby, D. (2005). Understanding the Capacity of Religious Organizations. Toronto, ON: Imagine Canada.

Bryant, A. N. (2006). Assessing the gender climate of an evangelical student subculture in the United States. Gender and Education, 18(6), 613-634.

Bryant, A. N. (2009). Negotiating the complementarian gender ideology of an evangelical student subculture: Further evidence from women's narratives. Gender and Education, 21(5), 549-565.

Bryk, A. S., Lee, V. E., \& Holland, P.B. (1993). Catholic schools and the common good. Cambridge, MA: Harvard University Press.

Burdette, A. M., Ellison, C. G., Hill, T. D., \& Glenn, N. D. (2009). "Hooking up" at college: Does religion make a difference? Journal for the Scientific Study of Religion, 48(3), 535-551.

Cantor, D., Fisher, B., Chibnall, S., Townsend, R., Lee, H., Bruce, C. \& Thomas, G. (2015). AAU climate survey on sexual assault and sexual misconduct. Retrieved from https://www.aau.edu/Climate-Survey.aspx?id=16525

Carr, J. L. (2005). American college health association campus violence white paper. Baltimore, MD: American College Health Association. Retrieved from http://www. nccpsafety.org/assets/files/library/ACHA_Campus_Violence_White_Paper.pdf

Cass, A. I. (2007). Routine activities and sexual assault: An analysis of individual- and school-level factors. Violence and Victims, 22(3), 350-366.

CCCU. No date. Council for Christian Colleges and Universities. Retrieved from http:// cccu.org

CHEC. No date. CHEC the facts. Christian Higher Education Canada. Retrieved from http://www.checanada.ca/about-us/chec-facts/

Chonody, J., Woodford, M. R., Smith, S., \& Silverschanz, P. (2013). Christian social work students' attitudes towards lesbians and gay men: Religious teachings, religiosity, and contact. Journal of Religion \& Spirituality in Social Work, 32(3), 211-226.

Cohen, N. L. (2012). Delirium: How the sexual counterrevolution is polarizing America. Berkeley, CA: Counterpoint.

Coleman, J. S., Hoffer, T. B., \& Kilgore, S. (1982). Cognitive outcomes in public and private schools. Sociology of Education 55(2), 65-76. 
Cook, S. L., Gidycz, C. A., Koss, M. P., \& Murphy, M. (2011). Emerging issues in the measurement of rape victimization. Violence Against Women, 17(2), 201-218.

Daloz Parks, S. (2000). Big questions: Mentoring young adults in their search for meaning, purpose, and faith. San Francisco, CA: Jossey-Bass.

DeKeseredy, W. S., \& Kelly, K. (1993). The incidence and prevalence of woman abuse in Canadian university and college dating relationships. Canadian Journal of Sociology, 18(2), 137-159.

DeKeseredy, W. S., \& Schwartz, M. D. (2013). Male peer support and violence against women. Boston, MA: Northeastern University Press.

Donovan, J. (2000). Feminist theory (3rd Ed.). New York, NY: Continuum.

Eberstadt, M. (2012). Adam and Eve after the pill: Paradoxes of the sexual revolution. San Francisco, CA: Ignatius Press.

Ellison, C. G., \& Anderson, K.L. (2001). Religious involvement and domestic violence among U.S. couples. Journal for the Scientific Study of Religion, 4O(2), 269-286.

Ellison, C. G., Bartkowski, J. P., \& Anderson, K. L. (1999). Are there religious variations in domestic violence? Journal of Family Issues, 2O(1), 87-113.

Ellison, C. G., Trinitapoli, J. A., Anderson, K. L., \& Johnson, B.R. (2007). Race/ ethnicity, religious involvement, and domestic violence. Violence Against Women 13(11), 1094-1112.

Fedina, L., Holmes, J. L., \& Backes, B. L. (2016). Campus sexual assault: A systematic review of prevalence research from 2000 to 2015. Trauma, violence, \& abuse, 1-18. doi: $10.1177 / 1524838016631129$

Fisher, B. S., Cullen, F. T., \& Turner, M. G. (2000). The sexual victimization of college women. Washington, DC: U.S. Department of Justice, Office of Justice Programs, National Institute of Justice, Bureau of Justice Statistics.

Fleck-Henderson, A. (2012). Beyond Title IX: Guidelines for preventing and responding to gender-based violence in higher education. Futures Without Violence/ Avon Foundation for Women. Retrieved from http://www.futureswithoutviolence.org/ userfiles/file/PublicCommunications/beyondtitleIXfinal.pdf

Fowler, F. J., Jr. (1993). Survey research methods (2nd Ed.). Newbury Park, CA: Sage.

Freitas, D. (2008). Sex and the soul: Juggling sexuality, spirituality, romance, and religion on America's college campuses. New York, NY: Oxford University Press.

Freitas, D. (2013). The end of sex: How hookup culture is leaving a generation unhappy, sexually unfulfilled, and confused about intimacy. New York, NY: Basic Books.

Gidney, C. (2004). A long eclipse: The liberal protestant establishment and the Canadian university 1920-1970. Montreal, PQ \& Kingston, ON: McGill-Queen's University Press.

Glanzer, P. L., Carpenter, J. A., \& Lantinga, N. P. (2011). Looking for God in the university: Examining trends in Christian higher education. Higher Education. 6, 721-755. 
Glanzer, P. L., Rine, P. J., \& Davignon, P. (2013). Assessing the denominational identity of American evangelical colleges and universities, Part I: Denominational patronage and institutional policy, Christian Higher Education, 12(3), 181-202.

Ginn, S. R., Walker, K., Poulson, R. L., Singletary, S. K., Cyrus, V. K., \& Picarelli, J. A. (1998). Coercive sexual behavior and the influence of alcohol consumption and religiosity among college students in the Bible belt. Journal of Social Behavior and Personality, 13(1), 151-165.

Giovannelli, T. S, \& Jackson, L. (2009). Sexual violence perceptions among Christian college students. Mental Health, Religion \& Culture. 16(3), 254-272.

Hall, M. H., Barr, C. W., Easwaramoorthy, M. W., Sokolowski, S., \& Salamon, L. M. (2005). The Canadian nonprofit and voluntary sector in comparative perspective. Toronto, ON: Imagine Canada.

Heise, L. L. (1998). Violence against women: An integrated, ecological framework. Violence Against Women 4(3), 262-290.

Hill, J. P. (2009). Higher education as moral community: Institutional influences on religious participation during college, Journal for the Scientific Study of Religion, 48(3), 515-534.

Hines, D. A. (2007). Predictors of sexual coercion against women and men: A multilevel, multinational study of university students. Archives of Sexual Behavior, 36, 403-422.

Jankoski, P. J., Johnson, A. J., Damron, J. E. H., \& Smischney, T. (2011). Religiosity, intolerant attitudes, and domestic violence myth acceptance. International Journal for the Psychology of Religion, 21,163-182.

Jeavons, T. (2004). Understanding religious organizations: Implications and concerns for public policy and social welfare services. In P. Frumkin \& J. Imber (Eds), In search of the nonprofit sector, pp.153-170. New Brunswick, NJ: Transaction.

Kinser, K., Levy, D. C., Silas, J. C., Bernasconi, A., Slantcheva-Durst, S., Otieno, . . . LaSota, R. (2010). The growth of global private education. San Francisco, CA: JosseyBass.

Koch, J. R., \& Ramirez, I. L. (2010). Religiosity, Christian fundamentalism, and intimate partner violence among U.S. college students. Review of Religious Research 51(4), 402-410

Koss, M. P., Abbey, A., Campbell, R., Cook, S., Norris, J., Testa, M., . . . \& White, J. (2007). Revising the SES: A collaborative process to improve assessment of sexual aggression and victimization. Psychology of Women Quarterly, 31, 357-370.

Koss, M. P., \& Gidycz, C. A. (1985). Sexual Experiences Survey: Reliability and validity. Journal of Consulting and Clinical Psychology, 53(3), 422-423.

Koss, M. P., Gidycz, C. A., \& Wisniewski, N. (1987). The scope of rape: Incidence and prevalence of sexual aggression and victimization in a national sample of higher education students. Journal of Consulting and Clinical Psychology, 55(2), 162-170. 
Koss, M. P., \& Oros, C. J. (1982). Sexual Experiences Survey: A research instrument investigating sexual aggression and victimization. Journal of Consulting and Clinical Psychology, 5o(3), 455-457.

Krebs, C. P., Lindquist, C. H., Warner, T. D., Fisher, B. S., \& Martin, S. L. (2007). The Campus Sexual Assault Study. Washington, DC: National Institute of Justice. Retrieved from https://www.ncjrs.gov/pdffiles1/nij/grants/221153.pdf

Krebs, C. P., Lindquist, C. H., Warner, T. D., Fisher, B. S., Martin, S. L. \& Childers, J. M. (2011). Comparing sexual assault prevalence estimates obtained with direct and indirect questioning techniques, Violence Against Women, 17(2), pp. 219-235.

Lawson, J. (2012). Sociological theories of intimate partner violence. Journal of Human Behavior in the Social Environment. 22, 572-590.

Levy, B. (2008.) Women and violence. Berkeley, CA: Seal Press.

Lidzy, S. D. (2005). Gender role expectations of students at a Christian university: Cultural notions of masculinity and femininity. Christian Higher Education, 4, 317-332.

McCallum,E.B.,\&Peterson,Z.D.(2016).Women'sself-reportofsexualvictimization:An experimental examination of the influence of race, mode of inquiry, setting, and researcher contact.Violence Against Women, 1-21. doi: https://doi.org/10.1177/1077801216651338

Mohler-Kuo, M., Dowdall, G. W., Koss, M. P., \& Wechsler, H. (2004). Correlates of rape while intoxicated in a national sample of college women. Journal of Studies on Alcohol, 65(1), 37-45.

Mustaine, E. E., \& Tewksbury, R. (2002). Sexual assault of college women: A feminist interpretation of a routine activities analysis. Criminal Justice Review 27(1), 89-123.

Neal, C. J. \& Mangis, M. W. (1995). Unwanted sexual experiences among Christian college women: Saying no on the inside. Journal of Psychology and Theology, 23(3), 171-179.

Nicholson, M. E., Wang, M. Q., Maney, D., Yuan, J., Mahoney, B. S., \& Adame, D. D. (1998). Alcohol related violence and the unwanted sexual activity on the college campus. American Journal of Health Studies, 14(1), 1-11.

Paluck, E. L., \& Shepard, H. (2012). The salience of social referents: A field experiment on collective norms and harassment behavior in a school social network. Journal of Personality and Social Psychology 103(6), 899-915.

Parry, M. (2015). Behind the statistics on campus rape. Chronicle of Higher Education, 61(18). Retrieved from http://chronicle.com/article/Behind-the-Statistics-on/151089/

Regnerus, M. D. (2003). Moral communities and adolescent delinquency: Religious contexts and community social control. Sociological Quarterly, 44(4), 523-554.

Riley, N. S. (2005). God on the quad: How religious colleges and the missionary generation are changing America. New York, NY: St. Martin's Press.

Quinlan, E., Clark, A. \& Miller, N. (2016). Enhancing care and advocacy for sexual assault survivors on Canadian campuses. Canadian Journal of Higher Education, 46 (2), 40-54.

Salamon, L. (1995). Partners in public service: Government-nonprofit relations in the modern welfare state. Baltimore, MD: Johns Hopkins University Press. 
Sawa, T., \& Ward, L. (2015). Sex assault reporting on Canadian campuses worryingly low, say experts. CBC News. Retrieved from http://www.cbc.ca/news/canada/sexassault-reporting-on-canadian-campuses-worryingly-low-say-experts-1.2948321

Schwartz, M. D., \& DeKeseredy, W. S. (1997). Sexual assault on the college campus: The role of male peer support. Thousand Oaks, CA: Sage.

Schwartz, M. D., DeKeseredy, W. S., Tait, D., \& Alvi, S. (2001). Male peer support and a feminist routine activities theory: Understanding sexual assault on the college campus. Justice Quarterly 18(3), 623-649.

Schuman, S. (2010). Seeing the light: Religious colleges in twenty-first-century America. Baltimore, MD: Johns Hopkins University Press.

Sheriff, M., \& Sheriff, C. (1964). Reference groups: Exploration into conformity and deviation in adolescents. Chicago, IL: Henry Regnery.

Smith, D. (2013). Differentiation and diversification in higher education: The case of private faith-based higher education in Manitoba. Canadian Journal of Higher Education, 43(1), 23-43.

Smith, S. R. (2014). Hybridity and nonprofit organizations: The research agenda. American Behavioral Scientist. 58(11), 1494-1508.

Smith, S. R., \& Lipsky, M. (1993). Nonprofits for hire: The welfare state in the age of contracting. Cambridge, MA: Harvard University Press.

Stark, R. (1996). Religion as context: Hellfire and delinquency one more time, Sociology of Religion, 57(2), 163-174.

Straus, M. A. (1979). Measuring intrafamily conflict and violence: The Conflict Tactics (CT) Scales. Journal of Marriage and the Family, 41, 75-88.

Straus, M. A. (1990). Measuring intrafamily conflict and violence: The Conflict Tactics Scale. In M. A. Straus \& R. J. Gelles, Physical violence in American families: Risk factors and adaptations to violence in 8,145 families, pp. 29-47. New Brunswick, NJ: Transaction.

Straus, M. A. (2004a). Cross-cultural reliability and validity of the Revised Conflict Tactics Scales: A study of university student dating couples in 17 nations. Cross-Cultural Research, 38(4), 407-432.

Straus, M. A. (2004b). Prevalence of violence against dating partners by male and female university students worldwide. Violence Against Women, 1O(7), 90-811.

Straus, M. A. (2012). Blaming the messenger for the bad news about partner violence by women: The methodological, theoretical, and value basis of the purported invalidity of the Conflict Tactics Scales. Behavioral Sciences \& the Law. 30(5), 538-556.

Straus, M. A., \& Douglas, E. M. (2004). A short form of the revised Conflict Tactics Scale, and typologies for severity and mutuality. Violence and Victims, 19(5), 507-520.

Testa, M., VanZile-Tamsen, C., Livingston, J. A., \& Koss, M. P. (2004). Assessing women's experiences of sexual aggression using the Sexual Experiences Survey: Evidence for validity and implications for research. Psychology of Women Quarterly, 28(3), 256-265. 
Trick, D. (2015). Affiliated and federated universities as sources of university differentiation. Toronto, ON: Higher Education Quality Council of Ontario.

Vanderwoerd, J.R. (2009). Experiences of sexual coercion, awareness of services, and acceptance of rape myths among students in rural colleges. Rural Social Work \& Community Practice, 14(1), 17-28.

Wang, M., Horne, S. G., Levitt, H. M., \& Klesges, L. M. (2009). Christian women in IPV relationships: An exploratory study of religious factors. Journal of Psychology and Christianity 28(3), 224-235.

Westwood, R. (2016). Canadian schools need to start treating sexual assault survivors less as victims and more as experts. Metro Toronto. Retrieved from http://www. metronews.ca/features/unsafe-space/2016/10/o7/schools-need-to-treat-sex-assaultsurvivors-as-experts.html

Wuthnow, R. (2004). Saving America? Faith-based services and the future of civil society. Princeton, NJ: Princeton University Press.

\section{Contact Information}

James R. Vanderwoerd

Department of Applied Social Sciences

Redeemer University College

jwoerd@redeemer.ca

James R. Vanderwoerd is a professor in the Department of Applied Social Sciences at Redeemer University College in Hamilton, Ontario. He completed an MSW at Wilfrid Laurier University and a PhD in social welfare at Case Western Reserve University. His research and teaching interests are in the prevention of violence against women on college campuses, religion and secularization in social welfare, and social welfare policy and history.

Albert Cheng is a postdoctoral fellow for the Program on Education Policy and Governance at Harvard University. He completed his PhD in education policy at the University of Arkansas where he is an affiliated research fellow for Charassein: The Character Assessment Initiative. 